\title{
APRENDENDO MATEMÁTICA POR COMPREENSÃO - UMA PRÁTICA REALIZADA NO CURSO DE ADMINISTRAÇÃO
}

\author{
LEARNING MATHEMATICS BY UNDERSTANDING - \\ A PRACTICE PERFORMED IN THE ADMINISTRATION COURSE \\ DIONEI CARDOZO* \\ JANAINA POFFO POSSAMAI** \\ JULIANA MENEGHELLI***
}

\section{RESUMO}

0 estudo teve como objetivo analisar quais as implicações da Resolução de Problemas como um caminho para se fazer Matemática com compreensão (Making Sense), para a aprendizagem dos conceitos de razão, proporção, regra de três simples e composta e porcentagem, no contexto do curso superior de Administração. Para tanto, foi planejada e aplicada uma abordagem de ensino na disciplina de Matemática Básica, cujos resultados foram analisados com base nas dimensões do Making Sense. Verificou-se que os acadêmicos passaram a ser protagonistas na construção de seu conhecimento, se tornando confiantes em suas habilidades de fazer matemática, se expressando crítica e criativamente na tomada de decisão para a resolução dos problemas propostos no contexto da Administração.

Palavras-chave: Making Sense. Matemática Básica. Administração.

\section{ABSTRACT}

The study aimed to analyze the implications of Problem Solving as a way to do Mathematics with Understanding (Making Sense), to learn the concepts of reason, proportion, rule of three simple, compound and percentage, in the context of the upper Administration course. For that, a teaching approach was planned and applied in the Basic Mathematics discipline, whose results were analyzed based on the dimensions of the Making Sense. It was found that academics became protagonists in building their knowledge, becoming confident in their ability to do math, expressing themselves critically and creatively in decision-making to solve the problems proposed in the context of the Administration.

Keywords: Making Sense. Basic Mathematics; Administration.

\footnotetext{
* Mestre em Ensino de Ciências Naturais e Matemática (FURB). Universidade Regional de Blumenau. E-mail: dionei.cardozo95@gmail.com. Orcid: http://orcid.org/0000-0003-0850-9664

** Doutora em Engenharia de Produção (UFSC). Universidade Regional de Blumenau. E-mail: janai-nap@furb.br. Orcid: http://orcid.org/ 0000-0003-3131-9316

*** Mestre em Ensino de Ciências Naturais e Matemática (FURB). Universidade Regional de Blumenau. E-mail: juliana.meneghelli@hotmail.com. Orcid: http://orcid.org/ 0000-0001-5308-8999
} 


\section{INTRODUÇÃO}

Uma das tendências atuais, no que se refere ao ensino de Matemática é a metodologia de Resolução de Problemas, pois é por meio da busca por soluções, ao invés da resolução de exercícios rotineiros, que 0 estudante desenvolve a compreensão Matemática. Tal metodologia se constitui como um caminho para fazer e aprender Matemática com compreensão, que é conhecido na literatura internacional pelo termo Making Sense.

Nessa perspectiva de ensino, os problemas são discutidos em grupos, que compartilham e discutem ideias em busca estratégias. Os estudantes são responsáveis por argumentar sobre seus caminhos de solução, eles testam hipóteses, fazem conjecturas, validam e justificam suas soluções (VAN DE WALLE, 2009).

Nessa perspectiva Allevato e Onuchic (2014) propõem a Metodologia de Ensino-Aprendizagem-Avaliação de Matemática através da Resolução de Problemas, na qual os problemas são apresentados no início e são denominados problemas geradores pois visam a construção de um novo conceito ou conteúdo matemático, se constituindo como meios de aprender matemática. Nessa metodologia, o estudante é o protagonista da construção do seu conhecimento e o professor o mediador, avaliando enquanto se resolve o problema.

Porém, essa prática dificilmente é utilizada em sala de aula e o que geralmente acontece é um ensino por instrução direta, em que o professor é responsável por transmitir o conteúdo e, ao estudante, cabe resolver exercícios ou situações contextualizadas com base nas técnicas e algoritmos ensinados. Denominada de ensinar para resolver problemas e é "[...] a concepção mais presente nas salas de aula e nos livros texto de Matemática, mas pode levar a configurar a resolução de problemas como uma atividade que os alunos só podem realizar após a introdução de um novo conceito" (ALLEVATO, 2014 , p. 213).

Numa perspectiva de mudança desse cenário, essa pesquisa está centrada no contexto do curso de Administração, cujas diretrizes curriculares nacionais indicam o desenvolvimento de competências e habilidades esperadas para o profissional da área, que direcionam para um ensino com compreensão, das quais destacam-se:

Reconhecer e definir problemas, equacionar soluções, pensar estrategicamente, introduzir modificações no processo produtivo, atuar preventivamente, transferir e generalizar conhecimentos e exercer, em diferentes graus de complexidade, o processo da tomada de decisão;

[...]

Desenvolver raciocínio lógico, crítico e analítico para operar com valores e formulações matemáticas presentes nas relações formais e causais entre fenômenos produtivos, administrativos e de controle, bem assim expressando-se de modo crítico e criativo diante dos diferentes contextos organizacionais e sociais (BRASIL, 2005. p. 2).

A abordagem de ensino da Matemática baseada no Making Sense vai ao encontro do que se espera da formação de um acadêmico do curso de Administração. Nessa perspectiva, tem-se estabelecido o problema de pesquisa como sendo "quais as implicações da Resolução de Problemas como um caminho para se fazer Matemática com compreensão, para aprendizagem dos conceitos de razão, proporção, regra de três simples e composta e porcentagem, no contexto do curso de Administração?". 
Para tanto, na sequência discute-se as concepções que norteiam uma prática de ensino baseada no Making Sense, bem como um estudo de caso em uma turma do curso de Administração.

\section{AS DIMENSÕES DO MAKING SENSE}

Ao conceber um ensino de Matemática que tenha como propósito o desenvolvimento da compreensão, é preciso repensar a maneira com a qual a prática pedagógica do professor está estruturada e quais as suas implicações na aprendizagem dos estudantes. Nesse contexto, Hiebert et al. (1997) descrevem cinco dimensões que, ao serem abordadas em conjunto, possibilitam efetivos ambientes de aprendizagem estruturados a partir de uma prática voltada ao Making Sense: (a) a natureza das tarefas de aprendizagem, (b) o papel do professor, (c) a cultura social da sala de aula, (d) o tipo de ferramentas matemáticas que estão disponíveis, e (e) a acessibilidade da matemática para cada estudante.

A respeito dessas dimensões, Hiebert et al. (1997, p. 7, tradução nossa) afirmam:

As dimensões que descrevemos podem ser consideradas conjuntos de recursos que estão agrupados em torno de temas comuns. Nenhuma dessas dimensões, por si só, é responsável pela criação de um ambiente de aprendizagem que facilite a construção da compreensão. Pelo contrário, todas elas trabalham em conjunto para criar tais ambientes. Cada uma delas é necessária, mas nenhuma delas, por si só, é suficiente.

É importante ressaltar que tais dimensões são provenientes dos estudos de diversos pesquisadores que integraram quatro diferentes projetos ${ }^{1}$ que tinham como intuito inicial um estudo a respeito da compreensão de estudantes quanto às operações aritméticas elementares. "Os quatro projetos foram todos concebidos com 0 objetivo de aumentar a compreensão dos estudantes. Evidências de atenção para as cinco dimensões das salas de aula são aparentes em cada projeto, mas com diferentes configurações e ênfases" (HIEBERT et al., 1997, p. 13, tradução nossa). Apesar do foco do estudo ter sido para o Ensino Fundamental, os autores apontam que muitas das observações e apontamentos constatados podem ser destinadas ao ensino e aprendizagem de Matemática de um modo geral. Assim, acredita-se que é plenamente possível implementar as mesmas práticas aqui descritas em outros contextos de aprendizagem, como o Ensino Superior, por exemplo.

\section{A NATUREZA DAS TAREFAS DE APRENDIZAGEM}

Atualmente, existem diversos instrumentos que possibilitam o ensino e aprendizagem de conceitos matemáticos, como jogos, problemas, recursos tecnológicos, dentre outros. Contudo, nenhum instrumento possibilitará a compreensão dos conteúdos se não estiver alinhado com os objetivos que se deseja alcançar em cada tarefa. Assim, faz-se necessário o desenvolvimento de efetivos instrumentos de aprendizagem que possibilitem, não apenas um fazer matemático mecânico e estruturado, mas principalmente, o desenvolvimento da compreensão a respeito do tópico em questão.

Face a essa situação, Hiebert et al. (1997) apontam que, acima de tudo, uma tarefa matemática deve permitir que os estudantes a abordem de maneira problemática, ou seja, algo que eles precisam refletir e discutir, em vez de simplesmente usar uma série de algoritmos pré-estabelecidos.

1 Os quatro projetos: (1) Cognitively Guided Instruction (CGI) - University of Winsconsin-Madison; (2) Conceptually Based Instruction (CBI) University of Delaware; (3) Problem Centered Learning (PCL) - University of Stellenbosch in South Africa; (4) Supporting Ten-Structured Thinking (STST) - Northwestern University. 
Além disso, 0 autor também afirma que 0 que deve ser problematizado em relação a tarefa escolhida, são os conceitos matemáticos e não outros aspectos da situação em questão. E por fim, de modo que os estudantes possam abordar a tarefa escolhida de maneira adequada, é preciso que ela ofereça a possibilidade de eles utilizarem as suas próprias habilidades e conhecimentos prévios para solucionar a atividade. Em outras palavras, as tarefas escolhidas precisam se configurar verdadeiros problemas a serem resolvidos. Deste modo, é válido apresentar a definição de problema proposta por Vila e Callejo (2006, p. 29) que se ajusta aos critérios enunciados acima.

Reservaremos, pois, o termo problema para designar uma situação, proposta com finalidade educativa, que propõe uma questão matemática cujo método de solução não é imediatamente acessível ao aluno/resolvedor ou ao grupo de alunos que tenta resolvê-la, porque não dispõe de um algoritmo que relaciona os dados e a incógnita ou de um processo que identifique automaticamente os dados com a conclusão e, portanto, deverá buscar, investigar, estabelecer relações e envolver suas emoções para enfrentar uma situação nova.

Essa concepção rompe com o modelo tradicional de ensino no qual é atribuído ao professor 0 papel de transmitir os conhecimentos, enquanto que os estudantes simplesmente os recebem, como um objeto pronto e acabado, que não necessita de novas modificações e nem exige uma reflexão a seu respeito. "As tarefas ou problemas podem e devem ser propostos de modo a envolver os alunos no pensar e desenvolver a matemática importante que eles precisam aprender" (VAN DE WALLE, 2009, p. 56).

Para haver essa compreensão matemática, Hiebert et al. (1997) apontam que existem dois processos fundamentais que precisam ser desenvolvidos pelos estudantes: a reflexão e a comunicação. $\mathrm{Na}$ visão dos autores, somente quando o estudante reflete sobre o que está desenvolvendo e interage com os demais, comunicando e trocando ideias, é que uma atividade matemática pode possibilitar a sua compreensão e o seu entendimento.

Refletir significa transformar algo em sua cabeça, pensando novamente sobre isso, tentando relacioná-lo com algo que você conhece. Se uma tarefa te encorajar a refletir sobre algo, você não se apressará em fazer o mais rápido que puder. Tarefas que incentivam a reflexão levam tempo. Comunicar significa falar e ouvir. Isso significa compartilhar 0 método desenvolvido para resolver um problema e responder a perguntas sobre seu método. Significa ouvir os outros compartilharem seus métodos e fazer perguntas para se certificar de que você entende (HIEBERT et al., 1997, p. 18, tradução nossa).

Ao propor uma atividade matemática que exija um pensar matemático apropriado, não apenas baseado em um conjunto de algoritmos já aprendidos, o professor possibilita à seus estudantes a oportunidade de elaborarem e refletirem a respeito de suas próprias estratégias de pensamento, questionando-se, aplicando seus próprios conhecimentos e desenvolvendo habilidades para novas situações, que não estejam diretamente relacionadas a essa atividade, mas que lhes serão úteis em outros momentos (VILA; CALLEJO, 2006).

Davis (1992) ${ }^{2}$ chama de "resíduos" a aprendizagem que os estudantes obtêm a partir dessa prática de Resolução de Problemas (apud HIEBERT et al., 1997), em outras palavras, é necessário que os problemas deixem algum tipo de conteúdo matemático de valor após a sua resolução.

2 Davis, R. B. Understanding “Understanding”. Journal of Mathematical Behavior 11: 225-241, 1992. 
Nesse contexto, a compreensão é desenvolvida como um resultado da Resolução de Problemas e não ensinada diretamente. Ainda é uma prática comum que leve em conta que para se aprender Matemática se deve ensinar, primeiramente, os conceitos importantes, explicando e demonstrando-os claramente como podem ser utilizados, para só depois, permitir que os estudantes pratiquem esses conceitos a partir da resolução de uma lista de exercícios (ALLEVATO, 2014). A ideia aqui proposta, é uma modificação desse panorama das aulas de Matemática. Sugere-se que, ao selecionar tarefas ou problemas, o professor leve em conta que tipo de conexões e resíduos os estudantes podem levar com eles e de que modo tais atividades podem possibilitar a construção de um novo conhecimento enquanto ocorre a sua resolução (HIEBERT et al., 1997). Contudo, tanto o papel do professor quanto do estudante, bem como a dinâmica da sala aula tendem a sofrer modificações.

\section{O PAPEL DO PROFESSOR}

Conforme já especificado, ao estabelecer um ambiente de aprendizagem que tem como intuito 0 entendimento matemático e não apenas a execução de técnicas ou algoritmos, o professor precisa alterar o seu papel em sala de aula. Nesse cenário, sua primeira tarefa é 0 desenvolvimento de efetivos problemas ou atividades que possibilitam o entendimento. "Isso significa que a seleção de tarefas apropriadas inclui pensar sobre como as tarefas estão relacionadas, como elas podem ser encadeadas para aumentar as oportunidades de os estudantes construírem gradualmente sua compreensão" (HIEBERT et al., 1997, p. 31, tradução nossa). Na concepção de Van de Walle (2009), os melhores problemas são aqueles que possibilitam múltiplos percursos de abordagens: existem diversos pontos de partida, bem como diferentes caminhos para se chegar às soluções. Assim, 0 problema torna-se acessivel para todo o grupo e não privilegia somente aqueles que têm mais facilidade com o método apresentado pelo professor.

Além disso, outra mudança importante no papel do professor na sala de aula é a quantidade de informações que ele fornece aos estudantes durante a resolução dos problemas. Hiebert et al. (1997) afirmam que, tradicionalmente, 0 ato de ensinar constituiu-se como uma prática de transmissão de informações e um ensino de qualidade era sinônimo de apresentar todas as informações de forma clara e direta, de modo que os estudantes pudessem compreender todos os aspectos daquele tópico sem a necessidade de consultar outras fontes, além do professor.

No entanto, na perspectiva de um ensino por compreensão, não significa que o professor deve se ausentar do processo de ensino e aprendizagem ou deixar que os estudantes resolvam todos os problemas sozinhos, sem auxílio. Acima de tudo, tem se direcionado o papel do professor ao de mediar o processo de resolução do problema, de modo que os "resíduos" que se deseja obter possam ser alcançados por todos os estudantes. Polya $(1995$, p. 1) fez seu alerta quanto a postura do professor durante a resolução de um problema:

Mas se ele for deixado sozinho, sem ajuda ou com auxílio insuficiente, é possível que não experimente qualquer progresso. Se o professor ajudar demais, nada restará para 0 aluno fazer. 0 professor deve auxiliar, nem demais nem de menos, mas de tal modo que ao estudante caiba uma parcela razoável de trabalho.

Nesse cenário, o professor não fornece respostas prontas aos questionamentos dos estudantes, mas incita-os a pensarem por si só, incentivando-os e propondo novas indagações que thes 
permitam, a partir de seus próprios conhecimentos, obter uma resposta ao problema e, consequentemente, aprender novos conteúdos. "Em outras palavras, a informação pode e deve ser compartilhada desde que não resolva o problema, não elimine a necessidade de os estudantes refletirem sobre a situação e desenvolverem métodos de solução que eles entendam" (HIEBERT et al., 1997, p. 36, tradução nossa). Outrossim, essa perspectiva também é descrita por Onuchic (1999, p. 216), ao se referir ao papel do professor num formato de aula a partir da Resolução de Problemas:

Dentro desse trabalho, o papel do professor muda de comunicador de conhecimentos para o de observador, organizador, consultor, mediador, interventor, controlador e incentivador da aprendizagem. 0 professor lança questões desafiadoras e ajuda os alunos a se apoiarem, uns nos outros, para atravessar as dificuldades. 0 professor faz a intermediação, leva os alunos a pensar, espera que eles pensem, dá tempo para isso, acompanha suas explorações e resolve, quando necessário, problemas secundários.

Desse modo, a sala de aula se torna um ambiente propício à troca de ideias e submete 0 estudante ao papel de agente ativo de sua própria aprendizagem, cabendo ao professor a responsabilidade de guiá-lo durante esse percurso.

Por fim, Hiebert et al. (1997) também apontam a importância de o professor assumir uma posição de autoridade apropriada para essa prática de aprendizagem. Na visão dos autores, o professor não deve ser a autoridade máxima em sala de aula para apontar a solução correta diretamente, sem a devida problematização de cada situação. Tal conclusão deve vir de uma discussão coletiva, de modo que faça sentido para toda a turma. "A palavra final é fornecida pela lógica do sujeito e pelas explicações e justificativas dos alunos que são construídas sobre essa lógica. [...] todos concordarão com a resposta correta para um problema se entenderem o problema e pensarem nisso por tempo suficiente." (HIEBERT et al., 1997, p. 40, tradução nossa). Essa prática possibilita ao estudante a autoconfiança e, acima de tudo, faz com que os métodos, a solução encontrada, as habilidades desenvolvidas e os conhecimentos construídos façam sentido para si próprio, de acordo com a sua abordagem perante 0 problema.

\section{A CULTURA SOCIAL DA SALA DE AULA}

A terceira dimensão descrita compete a uma oposição à clássica organização das aulas de Matemática, centrada na individualidade. 0 tradicional modelo de sala de aula, ainda presente em diversos estabelecimentos de ensino, composto de carteiras alinhadas em fileiras, incentiva a aprendizagem individual de cada estudante, reprime a comunicação e a troca de ideias, sustentando-se da premissa de que cada indivíduo é responsável pelo seu próprio conhecimento. Entretanto, por mais que essa premissa tenha sua relevância, ela não pode ser considerada em totalidade. Nesse contexto, Hiebert et al. (1997, p. 44, tradução nossa) fazem uma crítica a esse modelo de ensino e descrevem as dificuldades que ele acarreta para a compreensão matemática:

As formas tradicionais de instrução geralmente encorajam e até exigem que os estudantes trabalhem sozinhos. Trabalhar juntos ou usar as sugestões de um colega tem sido desencorajado. Os estudantes devem fazer o seu próprio trabalho e não confiar nos outros. Essa preocupação pode resultar, em parte, da importância que foi dada à avaliação das habilidades e do desempenho de cada aluno. Acreditamos que essa 
preocupação, que às vezes se tornou uma obsessão, teve um efeito destrutivo no clima e na cultura das salas de aula de matemática. É uma preocupação que excedeu os seus próprios alunos e transformou as salas de aula em ambientes artificiais que minam as tentativas dos alunos de fazer matemática. Fazer matemática é uma atividade colaborativa. Depende da comunicação e interação social.

Por conta desses motivos, defende-se nessa dimensão, que a compreensão matemática aconteça de maneira colaborativa, a partir de comunidades de aprendizagem. Nesse sentido, Cândido (2001, p. 16) descreve que "trocando experiências em grupo, comunicando suas descobertas e dúvidas, ouvindo, lendo e analisando as ideias dos outros, o aluno interioriza os conceitos e os significados envolvidos nessa linguagem e relaciona-os com suas próprias ideias". Assim, propõe-se que 0 ensino de Matemática esteja centrado na Resolução de Problemas em grupos, de modo que, a partir da colaboração e comunicação, a aprendizagem de novos conceitos se estabeleça como um resultado dessa prática. Ou ainda, mesmo quando os estudantes resolverem as atividades individualmente, é importante que existam momentos para discutir suas ideias com um ou mais colegas (VAN DE WALLE, 2009).

Hiebert et al. (1997) afirmam que, por meio das discussões dos métodos e da comparação das vantagens e desvantagens de cada um, os estudantes tendem a sair de sua zona de conforto, possibilitando a abordagem do problema a partir de uma nova maneira, aumentando a sua compreensão a respeito. "Diferentes estudantes apontam diferentes relações, diferentes aspectos do problema, diferentes abordagens para resolver os problemas. Aspectos que poderiam ter sido ignorados passam a ser notados. Novos tipos de compreensão tornam-se possíveis" (HIEBERT et al., 1997, p. 44, tradução nossa).

De igual modo, Van de Walle (2009, p. 74) aponta os benefícios de uma abordagem de ensino baseada a partir das comunidades de aprendizagem:

Enquanto os estudantes descrevem e avaliam as resoluções para as tarefas, compartilham abordagens e fazem conjecturas como membros de uma comunidade de aprendizes, alcançando modos de aprendizagens impossíveis de ocorrerem de outra maneira. Os alunos começam a ser autores de ideias e a desenvolver uma sensação de poder dar significado às ideias matemáticas.

Além disso, autores como Ruppenthal e Schetinger (2017) também afirmam que quando os estudantes têm a oportunidade de desenvolver e aplicar habilidades científicas, tais como a elaboração e teste de hipóteses, análise e organização de dados, confronto de informações, busca de soluções, dentre outras, propicia, além de posições argumentativas frente aos demais colegas, avanços em suas capacidades de resolução de problemas.

Por fim, não se espera com essa abordagem, propor que todas as aulas de Matemática aconteçam sempre em grupos. Acredita-se que há tempos e espaços adequados para atividades que contemplem também abordagens individuais. Contudo, deseja-se disseminar a ideia de que quando os estudantes resolvem problemas, que constituem efetivos ambientes de aprendizagem para novos conceitos, esses tendem a apresentar melhores resultados quando abordados e estruturados a partir das discussões e investigações coletivas que acontecem nessa perspectiva de aprendizagem. 


\section{FERRAMENTAS MATEMÁTICAS COMO SUPORTE DE APRENDIZAGEM}

Hiebert et al. (1997) definem como a quarta dimensão do Making Sense, o tipo de materiais ou ferramentas que estão disponíveis e que podem contribuir para o desenvolvimento da compreensão. De acordo com os autores, essas ferramentas podem ser a própria linguagem oral, materiais físicos, símbolos e até mesmo habilidades que os estudantes já possuam. Ao serem introduzidas na sala de aula, podem atuar como suportes externos para auxiliar a aprendizagem.

As ferramentas podem ser usadas de várias maneiras para ampliar a atividade matemática dos estudantes. Elas podem fornecer um registro conveniente e permanente da atividade matemática. Se os estudantes querem lembrar uma determinada quantidade ou ação, eles podem representá-la com palavras, materiais ou símbolos e, em seguida, usar esse registro posteriormente para recuperar a atividade. As ferramentas também podem fornecer uma maneira de se comunicar com outras pessoas. As palavras, é claro, são uma ferramenta de comunicação primária, mas materiais e símbolos escritos também podem ser usados dessa maneira. Finalmente, ferramentas podem ser usadas para pensar. Elas podem tornar os pensamentos difíceis mais fáceis de administrar: podem possibilitar alguns pensamentos que dificilmente seriam possíveis sem elas; e elas podem moldar os tipos de pensamentos que temos (HIEBERT et al., 1997, p. 53, tradução nossa).

Os autores afirmam que múltiplas ferramentas possibilitam diferentes formas de representação e que cada uma transmite uma mensagem diferente e enfatiza características da mesma ideia e isso é importante pois, criar relações entre essas representações possibilita novos caminhos para a compreensão (HIEBERT et al., 1997).

Essas ferramentas, sejam elas palavras, softwares ou objetos físicos, tais como calculadoras, imagens, cartazes, réguas, são todos materiais capazes de ampliar a compreensão durante a aprendizagem e podem ser utilizadas tanto para possibilitar a resolução de uma atividade, facilitar a compreensão de uma ideia, ou ainda, servir como apoio para justificar o método ou o raciocínio utilizado, perante os demais colegas. Em especial, à essa última opção, Hiebert et al. (1997) apontam que ao utilizarem ferramentas para compartilhar ideias, os estudantes contribuem não apenas para 0 seu próprio entendimento, mas também auxiliam na compreensão dos demais colegas. "Se eles têm algo para apontar, uma referência para a qual todos podem concentrar sua atenção, eles podem trabalhar em direção à entendimentos mais claros, mais bem articulados e mais amplamente compartilhados" (p. 58, tradução nossa).

Assim, reitera-se a importância que essas ferramentas representam para a aprendizagem matemática e a necessidade que o professor tem de saber incentivar e mediar a sua utilização, de modo a contribuir ainda mais para 0 entendimento dos conceitos pretendidos.

\section{EQUIDADE E ACESSIBILIDADE}

Como última dimensão considerada necessária por Hiebert et al. (1997) para haver uma aprendizagem baseada nos princípios do Making Sense, está uma componente considerada primordial e que perpassa por todas as outras dimensões já elencadas: a equidade da prática docente do professor que resulta em um processo de ensino e aprendizagem acessível para todos os estudantes. 
Van de Walle (2009) aponta que é notório a presença, por diversas vezes nos discursos tanto de pais, como de estudantes, que a Matemática é uma disciplina difícil e que somente pessoas com muita inteligência têm capacidade de entendê-la devidamente. Esse autor, inclusive, afirma que está cada vez mais comum encontrar pessoas que sentem orgulho em dizer "Eu nunca fui muito bom em matemática". É sobre esse cenário, por muitas vezes enraizado em nosso sistema de ensino, que essa última dimensão buscar atuar.

Aprender com compreensão por todas as crianças acontece quando os professores atendem especificamente à criação de um ambiente de sala de aula que leva em consideração a singularidade de cada indivíduo e atende às dimensões críticas das características de aprendizagem dos indivíduos - não quando os professores ignoram os grupos tradicionalmente insuficientes. Isso significa que cada criança tem a oportunidade de se envolver e refletir sobre tarefas que são matematicamente problematizadoras em uma comunidade social onde seu pensamento é discutido e valorizado (HIEBERT et al., 1997, p. 66, tradução nossa).

Contudo, não existem soluções prontas para esse problema. Mas, em contrapartida, o professor ao possibilitar um ambiente de aprendizagem baseado em comunidades, tem a sua disposição uma grande oportunidade de prover meios de acesso ao conhecimento a todos os estudantes de forma que, cada qual à sua própria maneira, possa contribuir na busca de soluções para efetivos problemas matemáticos. Para isso, é necessário, primeiramente, que o professor assuma uma postura de não mais condenar os erros dos estudantes e passar considerá-los como oportunidade para novas investigações. Acima de tudo, a sala de aula deve ser um ambiente convidativo para a troca de ideias, sejam elas corretas, do ponto de vista matemático, ou não. "A sala de aula deve ser um ambiente onde fazer matemática não seja ameaçador e onde todos os estudantes sejam respeitados por suas ideias. Os estudantes devem se sentir confortáveis em correr riscos e saber que eles não serão ridicularizados ao cometerem erros" (VAN DE WALLE, 2009, p. 33).

Além promover problemas que sejam acessíveis para todos os estudantes, o professor precisa mediar um processo que possibilite a participação de todo o grupo. Esse ambiente nem sempre é fácil de obter, contudo é papel do professor a sua busca constante. Nesse sentido, Hiebert et al. (1997, p. 67, tradução nossa) afirma que quanto mais discussões e novas ideias, mais compreensão da situação os estudantes possuirão:

É importante que todos os alunos compartilhem essa responsabilidade, porque todas as ideias e métodos são possíveis campos de aprendizagem. Métodos corretos são objetos apropriados de discussão, assim como os métodos incorretos. Uma variedade de ideias são essenciais para alimentar discussões ricas. A probabilidade de que a turma, como um grupo, tenha uma variedade de ideias sobre a mesa para discussão e análise aumenta à medida que mais estudantes encontram maneiras de participar. 0 grupo provavelmente fará maior progresso quando todos os estudantes participarem e oferecerem ideias e métodos para discussão.

Assim, ao propiciar um ambiente que possibilite a investigação matemática como uma prática para a busca de soluções, promovendo oportunidade para todos os estudantes se manifestarem e proporem ideias são os pilares fundamentais para subsidiar uma prática de ensino baseada na compreensão e não na repetição (VAN DE WALLE, 2009). 
Por fim, com 0 intuito de sistematizar todas essas dimensões, 0 Quadro 1 a seguir apresenta as características principais que perpassa todo esse estudo.

Quadro 1 - Dimensões do Making Sense.

\begin{tabular}{|l|l|}
\hline \multicolumn{1}{|c|}{ Dimensão } & \multicolumn{1}{c|}{ Características principais } \\
\hline A natureza das tarefas de aprendizagem & $\begin{array}{l}\text { Fazer a matemática problematizadora; } \\
\text { Conectar com o contexto dos estudantes; } \\
\text { Deixar como resíduos conceitos matemáticos importantes. }\end{array}$ \\
\hline 0 papel do professor & $\begin{array}{l}\text { Selecionar tarefas com objetivos em mente; } \\
\text { Compartilhar informações essenciais; } \\
\text { Estabelecer uma cultura de sala de aula. }\end{array}$ \\
\hline A cultura social da sala de aula & $\begin{array}{l}\text { Ideias e métodos são valorizados; } \\
\text { Estudantes escolhem e compartilham seus métodos; } \\
\text { Erros são campos de aprendizagem para todos; } \\
\text { A correção reside no argumento matemático. }\end{array}$ \\
\hline $\begin{array}{l}\text { Ferramentas matemáticas como suporte } \\
\text { de aprendizagem }\end{array}$ & $\begin{array}{l}\text { Significado para as ferramentas deve ser construído por cada usuário; } \\
\text { Usadas com propósito - para resolver problemas; } \\
\text { Usadas para gravar, comunicar e pensar. }\end{array}$ \\
\hline Equidade e acessibilidade & $\begin{array}{l}\text { As tarefas são acessíveis para todos os estudantes; } \\
\text { Cada estudante é ouvido; } \\
\text { Cada estudante contribui. }\end{array}$ \\
\hline
\end{tabular}

Fonte: Hiebert et al. (1997, p.12, tradução nossa).

\section{METODOLOGIA DE PESQUISA}

Com o intuito de verificar as implicações do Making Sense no Ensino Superior, sendo que as práticas comumente pesquisadas se referem à Educação Básica, planejou-se uma abordagem de ensino nesse contexto para a disciplina de Matemática Básica do curso de Administração da Universidade Regional de Blumenau. No primeiro semestre de 2018 essa disciplina foi ministrada pela professora e por dois mestrandos em Ensino de Ciências Naturais e Matemática na disciplina de Estágio Docência, sendo que esses além de atuarem como docentes tiveram o olhar de pesquisadores sobre a prática desenvolvida.

No primeiro módulo da disciplina, o plano de ensino prevê que sejam trabalhados os conteúdos de razão, proporção, regra de três simples e composta e porcentagem. Nesse contexto desenvolveu-se uma sequência de problemas cujos "resíduos" pretendidos eram os conteúdos do módulo, ou seja, esperava-se construir os conceitos por meio da resolução dos problemas propostos. Participaram dessa pesquisa 39 acadêmicos organizados em 10 grupos e a prática foi constituída de 5 problemas abordados sob a perspectiva das dimensões que orientam para um ensino com compreensão - Making Sense. É importante enfatizar que apenas um dos problemas abordados foi analisado nesse artigo.

A investigação resultante dessa prática constitui-se como uma pesquisa qualitativa, sendo fundamentada sua análise a partir da interpretação dos dados, atribuindo significado aos fenômenos observados. Os instrumentos de coleta e análise dados se constituíram a partir dos documentos que compõem as observações dos pesquisadores, de áudio e imagem e por meio dos recursos utilizados pelos acadêmicos para registrar suas soluções, como cadernos dos estudantes, cartazes e fóruns de discussão on-line. 
Como critérios de análise utilizou-se as cinco dimensões do Making Sense para verificar as implicações dessa prática no contexto da disciplina de Matemática Básica do curso de Administração.

De modo a construir os problemas, inicialmente foi realizada uma busca na internet a fim de encontrar notícias relacionadas com a área da Administração e que pudessem ser adaptadas de modo a desenvolver uma situação em que, a partir de sua problematização, os estudantes pudessem resolvê-las utilizando seus próprios conhecimentos com base nas discussões em equipes e que também possibilitassem a construção dos conceitos envolvidos. Foi proposto um problema para cada conceito pretendido, sendo que para regra de composta foram dois, e todas as equipes recebiam os mesmos problemas.

\section{ANÁLISE DA APLICAÇÃo}

Para a construção do conceito de razão e proporção, apresentou-se o problema "Como posso calcular o lucro de uma pequena empresa?" conforme ilustrado na Figura 1. 0 problema consistia de uma breve introdução extraída da notícia escolhida, cujo objetivo era a familiarização do estudante com o tema pretendido. A parte seguinte, que apresentava uma situação referente aos custos administrativos de uma empresa foi desenvolvida pelos autores e trata-se uma situação hipotética. Apesar de ser um problema que permitia múltiplos pontos de partida ou estratégias de resolução, existia uma única resposta correta.

Figura 1 - Problema proposto

\section{Como posso calcular o lucro de uma pequena empresa? \\ Fonte: https://www.jomalcontabil.com.br/como-posso-calcular-o-lucro-de-uma-pequena-empresa/}

Empreender é uma tarefa árdua, principalmente para pequenos empresários. Além das atividades operacionais, ainda é preciso administrar e garantir que o negócio tenha bons resultados, sempre mantendo um bom relacionamento com seus funcionários e parceiros de trabalho.

Entretanto, quando um profissional se prepara adequadamente, os obstáculos são superados e resultados positivos são obtidos. Por isso, calcular o lucro de uma pequena empresa é essencial para o seu bom gerenciamento.

Considere uma empresa cujas informações gerenciais para determinação do lucro de determinado produto estão descritas na tabela a seguir:

\begin{tabular}{|l|l|}
\hline Despesas administrativas & R\$ $5.000,00$ por mês \\
\hline Aluguel da fábrica & R\$ 880,00 por mês \\
\hline Custo com matéria-prima & $\begin{array}{l}\text { Cada lote para } 150 \text { peças é } \\
\text { adquirido por } \mathrm{R} \$ 7.800,00\end{array}$ \\
\hline Comissão & $\begin{array}{l}5 \% \text { sobre o preço de venda de } \\
\text { cada peça }\end{array}$ \\
\hline Preço de venda & $\mathrm{R} \$ 80,00$ por peça \\
\hline
\end{tabular}

Sendo você o administrador dessa empresa, qual seria a quantidade mínima de peças indicada como meta para o setor de vendas? Justifique sua resposta apresentando os cálculos que comprovem tal escolha.

Fonte: Adaptado pelos autores. 
A notícia / contexto do problema também se constituiu de um momento de problematização por si só, uma vez que foi discutida com o grupo de estudantes. Na sequência, a situação analisada e que foi resolvida pelos acadêmicos promoveu a construção de diversas hipóteses. Dentre elas, alguns grupos questionaram se o lote de matéria-prima seria adquirido sempre em quantidades fechadas de 150 peças ou se poderia ser fracionado. Frente à essa observação, no grande grupo, a discussão teve como consenso admitir pela compra de qualquer quantidade de matéria-prima, desde que se mantivesse a proporcionalidade do custo. Outra questão abordada foi 0 contexto da comissão, enquanto que alguns grupos entenderam que essa era recebida pela empresa ao vender os produtos, outros admitiram que ela era um custo pago aos vendedores de seus produtos - na busca de um consenso com turma, os acadêmicos chegaram à conclusão que, sendo uma empresa que não adquire e vende diretamente o produto acabado, mas que compra matéria-prima para produzir e então vender, entendeu-se que a comissão refere-se à um custo para a empresa.

Essa primeira problematização evidencia que 0 desenvolvimento do problema atendeu as concepções da primeira dimensão do Making Sense, uma vez que a natureza da atividade proposta estava direcionada para o contexto da Administração, problematizando a matemática envolvida e tendo como intuito deixar "resíduos" relacionados ao conceito de razão e proporção, podendo também, dependo do caminho de solução e dos recursos utilizados, construir os conceitos de regra de três simples e porcentagem.

As discussões iniciais fizeram parte de um momento de leitura dos problemas e discussão do contexto, na sequência os acadêmicos trabalharam em equipes para resolver a situação. Nesse trabalho em grupos, a professora e os estagiários eram solicitados com frequência para verificar se estavam resolvendo corretamente, sendo que os acadêmicos à todo momento queriam receber como resposta "está certo" ou "está errado, faça isso...", contudo com base na segunda e terceira dimensão, a abordagem aconteceu de modo que os mesmos indicavam os caminhos de discussão dos grupos realizando questionamentos que os fizessem refletir sobre suas decisões ao invés de apontar a direção de solução ou indicar certo ou errado, sendo que as argumentações matemáticas que eles usavam para justificar os procedimentos usados eram discutidas entre os integrantes do grupo.

Nas aulas tradicionais, quando o professor explica o conteúdo e os estudantes resolvem exercícios, implica que a maioria segue um procedimento padrão de solução, ou seja, há uniformidade no caminho de solução. Já a análise dos registros das soluções dos grupos para o problema proposto, permitiu perceber que os caminhos de solução e argumentação matemática foram diferentes, o que requereu maior tempo para correção e entendimento dos procedimentos usados pelos estudantes.

0 conceito de razão e proporção foi utilizado pelos estudantes, contudo os cálculos foram desenvolvidos com base nas operações de adição, subtração, multiplicação e divisão, não seguindo a estruturação habitualmente utilizada nesse conteúdo (produto dos meios é igual ao dos extremos). 
Parte dos grupos analisaram inicialmente o lucro obtido com a produção de 150 peças, pois foi a informação de lote fornecida, na sequência percebendo que haveria prejuízo, 5 grupos pautaram a resolução com base no cálculo do lucro por peça. A Figura 2 ilustra a resolução de dois grupos que organizaram a solução com base na mesma argumentação.

Figura 2 - Resolução do problema baseada no cálculo de lucro por peça

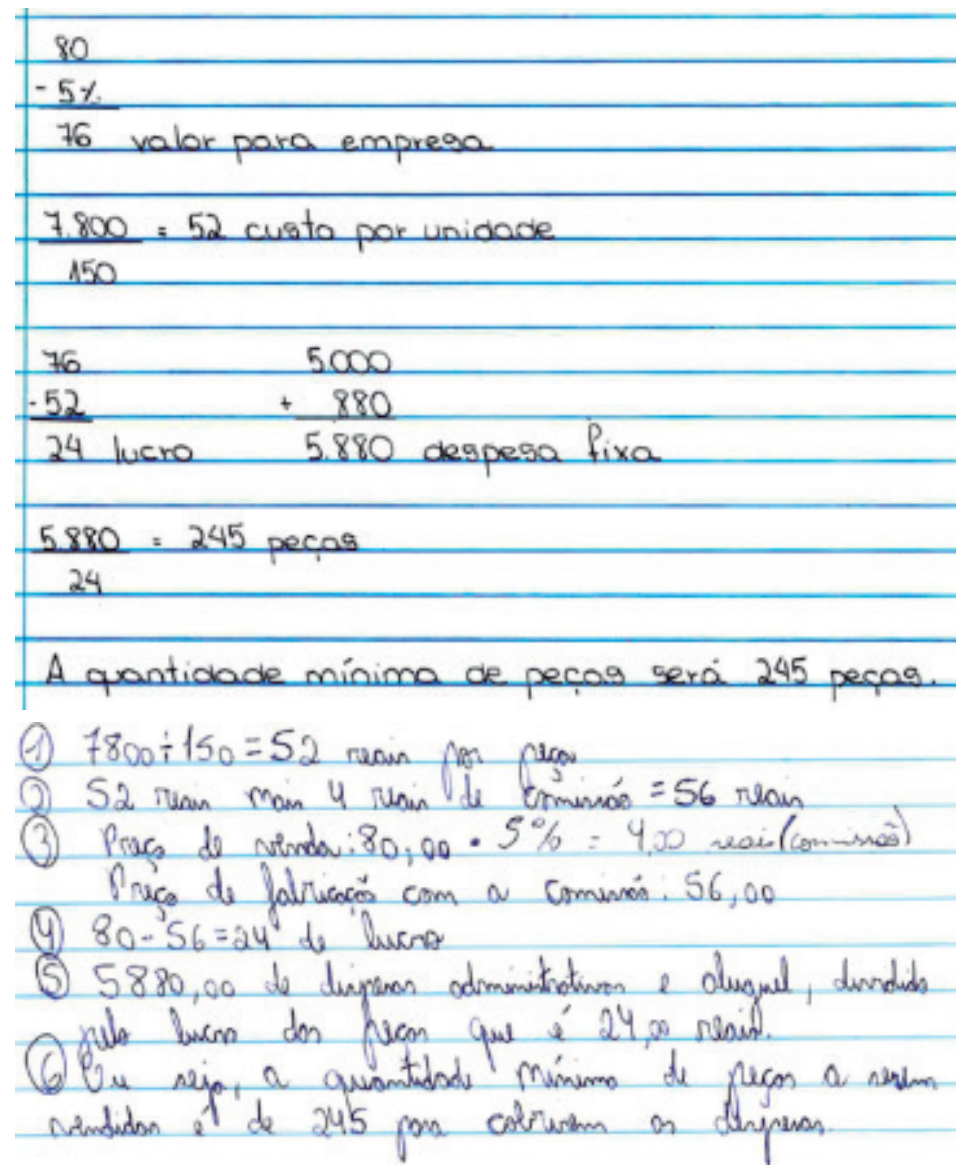

Fonte: Acervo de pesquisa dos autores.

Por outro lado, as outras 5 equipes usaram valores proporcionais aos obtidos com as 150 peças para chegar ao equilíbrio, igualando a receita com a despesa. A Figura 3 ilustra a resolução de duas equipes que utilizaram essa estratégia. 
Figura 3 - Resolução do problema baseada na ideia de proporcionalidade

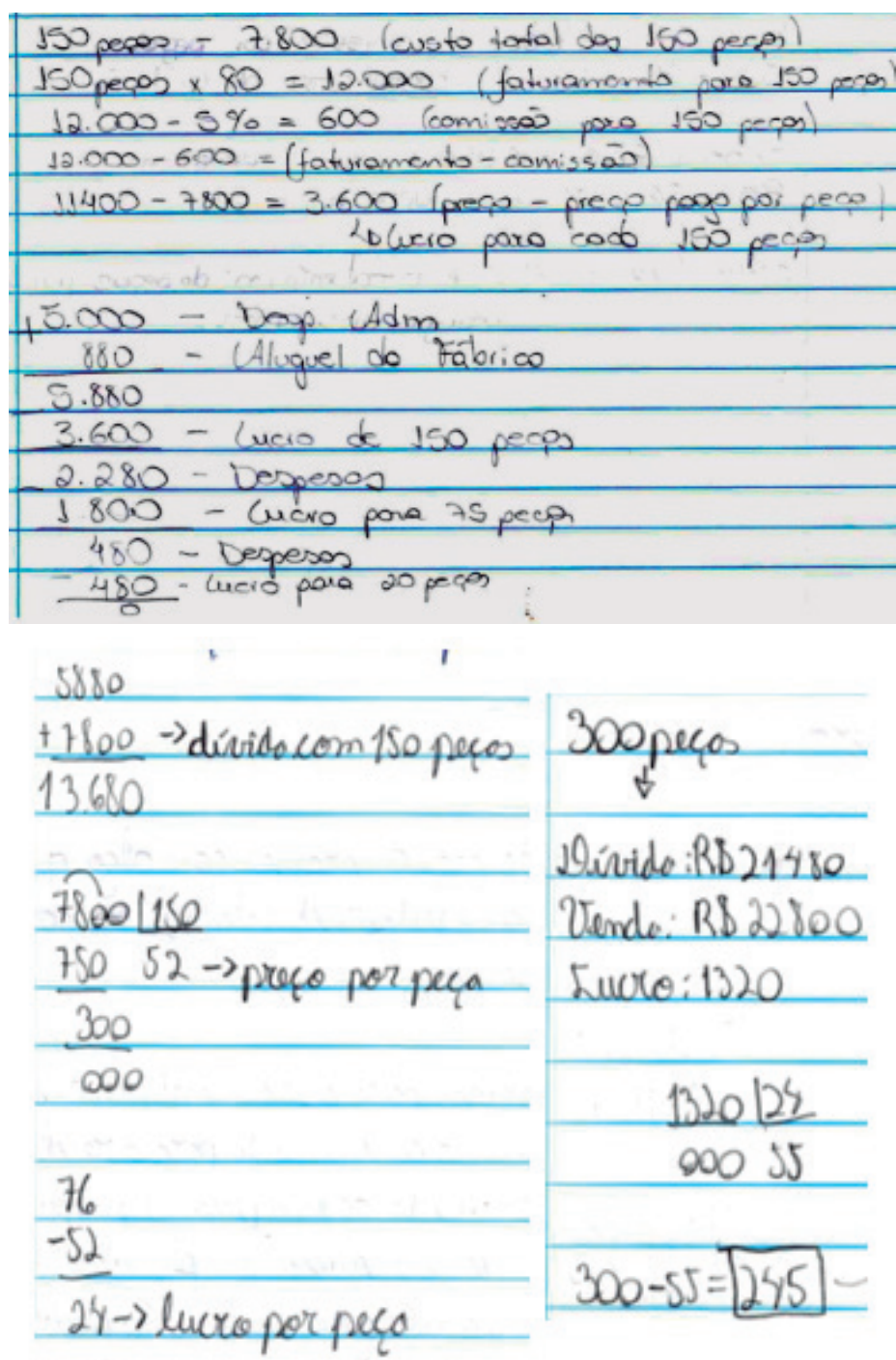

Fonte: Acervo de pesquisa dos autores.

Nos registros de observação, verificou-se que os acadêmicos utilizaram a calculadora como ferramenta para auxiliar a resolução, inclusive todas as equipes calcularam a porcentagem com base na função programada da calculadora. A descrição das estratégias de solução registradas no papel também se constitui de uma ferramenta de apoio para justificar os métodos utilizados para os demais colegas, tornando o processo de argumentação matemática mais fácil de administrar. Nesse aspecto tem-se verificada a quarta dimensão do Making Sense, que indica a importância do uso adequado de ferramentas para auxiliar no processo de construção do conhecimento. 
Ainda, no trabalho em grupo, é importante ressaltar que os acadêmicos eram incentivados para que todos participassem da resolução, possibilitando que todos fossem ouvidos e contribuíssem com a solução, sendo que a argumentação matemática de cada acadêmico permitia ao grupo chegar à um consenso de que caminho de solução seguir. Nesse sentido, pode-se perceber que a quinta dimensão do Making Sense é evidenciada nessa dinâmica de trabalho.

Após o término da etapa de resolução do problema, a turma passou a socializar os resultados, de modo que cada equipe argumentou sobre os procedimentos usados e a validade do resultado era avaliada pelos demais.

Outras quatro atividades com a mesma estruturação e abordagem foram aplicadas nas aulas seguintes, com finalidade de construir os demais conceitos mencionados. Nas primeiras atividades os acadêmicos pediam à professora e aos mestrandos que verificassem se estavam resolvendo corretamente, ou chamavam para esclarecer dúvidas, solicitando qual caminho de solução seguir. Como resposta à essas solicitações eram realizadas perguntas que os faziam refletir e argumentar matematicamente suas escolhas, de modo que eles discutissem e chegassem as suas próprias conclusões. Nesse processo, pode-se perceber um estranhamento inicial dos acadêmicos, mas gradativamente foi sendo construída a cultura social da sala de aula, na qual se modificava os preceitos tradicionais de transmissão de conteúdo para uma abordagem centrada no estudante e no seu protagonismo.

Nessa concepção o trabalho em grupo também foi sendo incentivado, pois inicialmente cada estudante resolvia e chamava a professora/mestrandos para verificar a validade, contudo conforme prosseguia-se nesse modelo de aula, eles passaram a validar suas soluções a partir da discussão e argumentação com os colegas do grupo, obtendo um consenso. Nessa abordagem, os erros deixaram de representar um obstáculo e passaram a fazer parte da resolução do problema, sendo abordados naturalmente como uma etapa a ser superada e entendidos como possibilidades para redirecionar os caminhos de solução, ou seja, os estudantes passaram a aprender com os erros cometidos. Nesse sentido, corrobora Van de Walle (2009, p. 50):

Uma confiança coletiva deve ser estabelecida com a compreensão de que é certo cometer erros. Os estudantes têm de perceber que os erros são uma oportunidade para crescimento quando são descobertos e explicados. Todos os estudantes devem confiar que suas ideias serão recebidas com o mesmo nível de respeito, independente de estarem corretas ou erradas. Sem essa confiança coletiva, muitas ideias nunca serão compartilhadas.

Analisando os registros e as discussões dos grupos, verificou-se que muitas das ideias iniciais incorretas, constituíram-se como pontos de partida para análise e direcionamento para soluções corretas, conforme ilustra a Figura 4. 
Figura 4 - 0 erro como parte da resolução do problema.

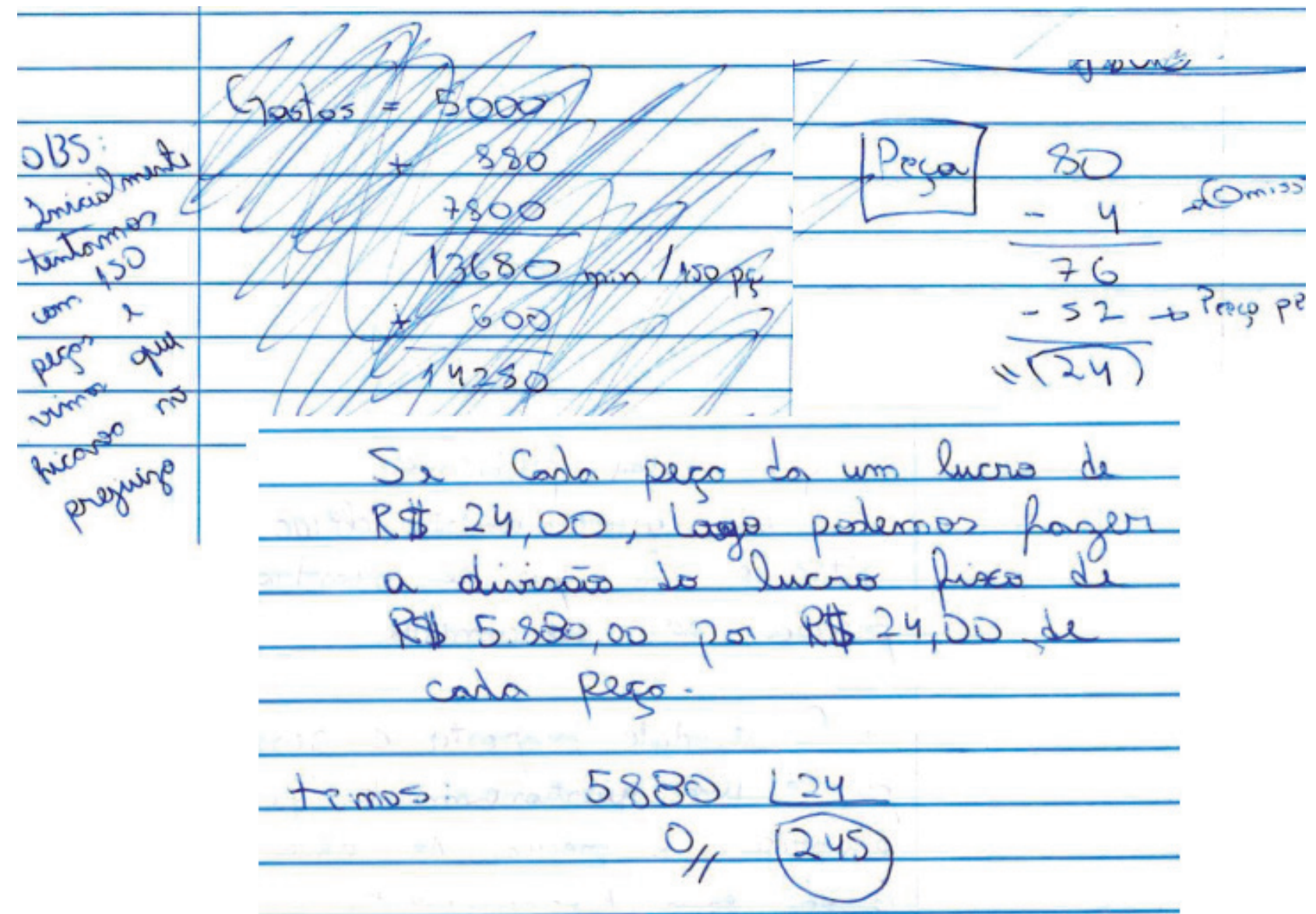

Fonte: Acervo de pesquisa dos autores.

Ao final das atividades, aplicou-se um questionário, que foi respondido por 35 acadêmicos que estavam presentes naquela aula, com 0 intuito de compreender as percepções dos acadêmicos frente a metodologia aplicada. A primeira pergunta questionava "Qual a sua opinião a respeito de aprender um conteúdo matemático através da resolução de um problema?". As respostas foram analisadas identificando 4 categorias, sendo que uma delas revela a valorização do contexto dos problemas relacionado com a prática profissional dos acadêmicos, a segunda evidencia a construção do conhecimento realizada pelo estudante, propiciando que o mesmo seja protagonista da aprendizagem, a outra confirma a importância da troca de experiências e 0 desenvolvimento de soluções no trabalho em grupo e, por fim, a que mostra a resistência em transcender o método de transmissão do conteúdo. Algumas dessas respostas podem ser verificadas na Figura 5: 
Figura 5 - Algumas respostas quanto à metodologia utilizada

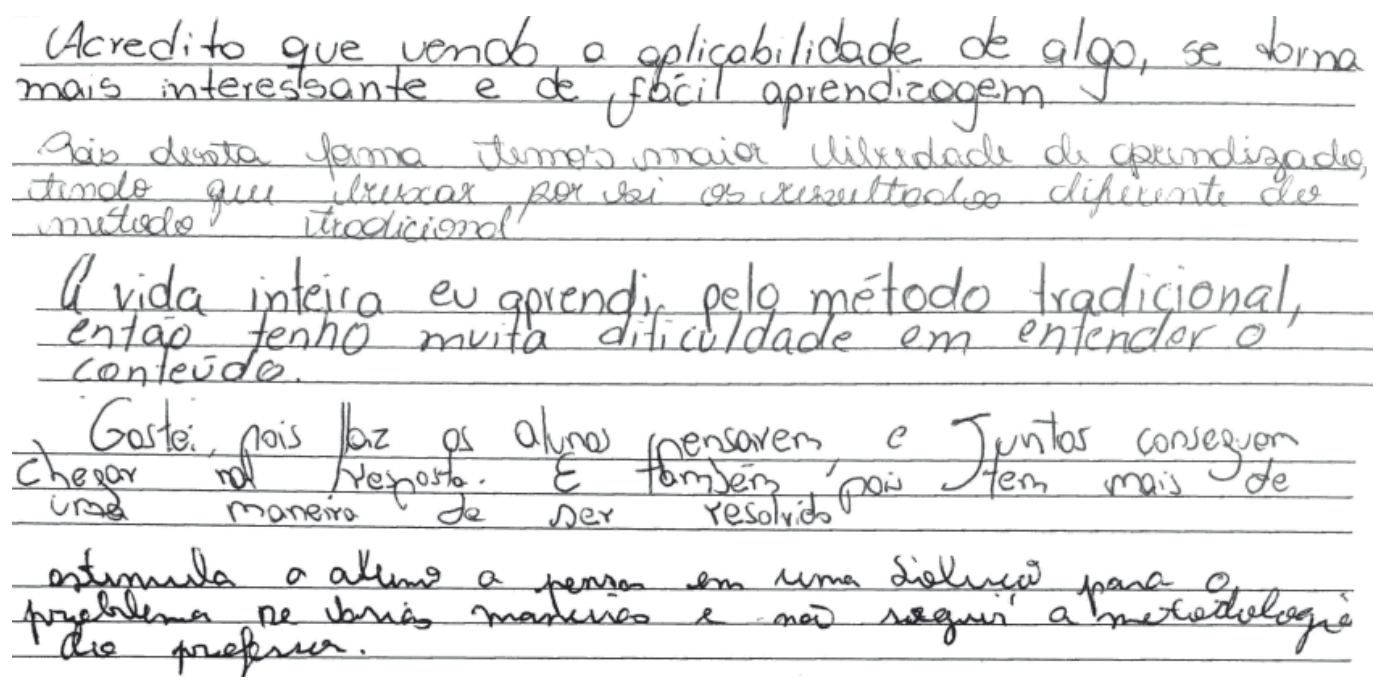

Fonte: Acervo de pesquisa dos autores.

Em relação às implicações dessa abordagem metodológica, na visão dos estudantes, foram elencadas as limitações percebidas por eles, conforme apresentado na Figura 6.

Figura 6 - Limitações da metodologia apontadas pelos estudantes

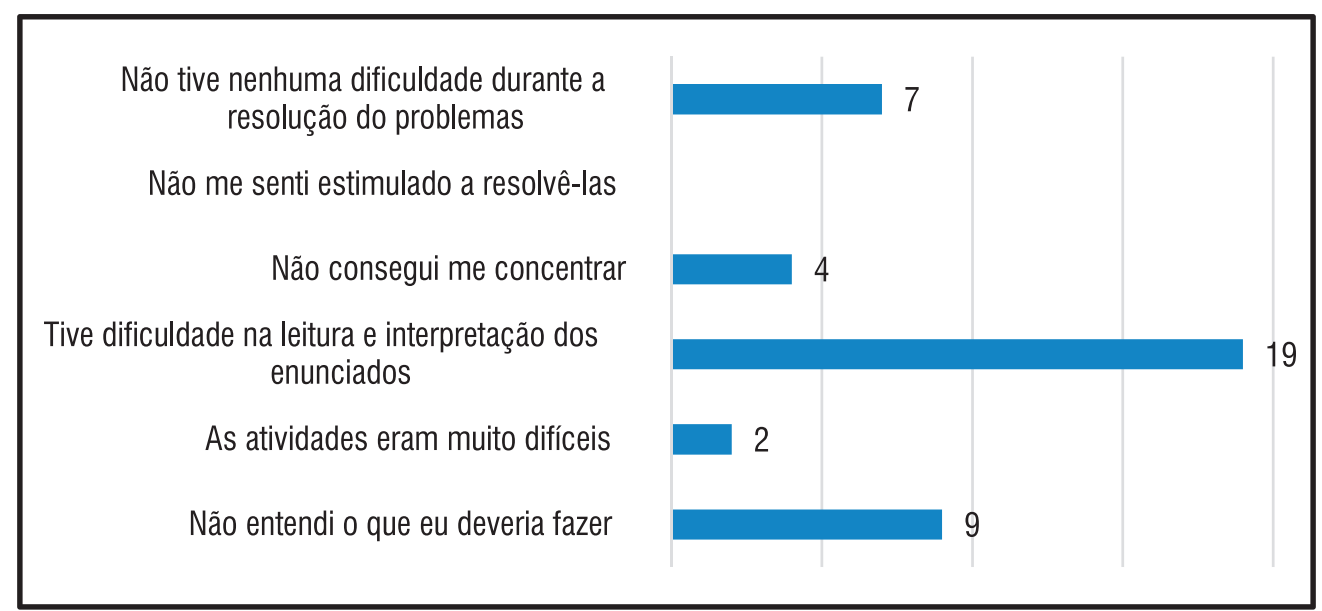

Fonte: Acervo de pesquisa dos autores.

Na resposta os acadêmicos puderam marcar mais de uma opção e verifica-se que a maior dificuldade está relacionada com a leitura e interpretação dos problemas, uma vez que, tradicionalmente, as situações matemáticas apresentam enunciados diretos que indicam a aplicação de um algoritmo ou técnica ensinados previamente pelo professor. Na metodologia utilizada, nenhum conteúdo foi previamente discutido com os estudantes, apenas ao final da plenária com o grupo e busca por um consenso é que a professora formalizou os conceitos. 
Uma segunda questão, abordava os pontos positivos verificados pelos estudantes, sendo que também puderam marcar mais de uma opção, conforme apresentado na Figura 7.

Figura 7 - Contribuições da metodologia apontadas pelos estudantes

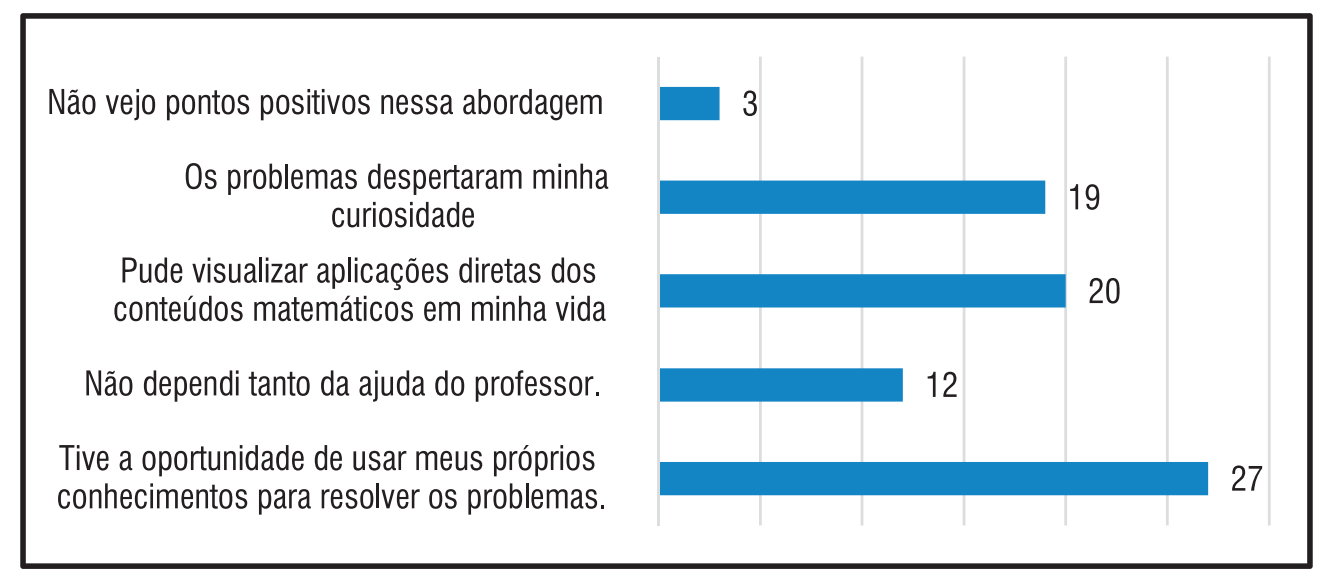

Fonte: Acervo de pesquisa dos autores.

Os resultados são condizentes com os relatos indicados na primeira pergunta do questionário e evidenciam que a proposta possibilitou ensinar matemática por compreensão, implicando em permitir que os estudantes fossem o "[...] centro da explicação, fornecendo evidências ou justificativas, encontrando ou criando exemplos, generalizando, analisando, fazendo previsões, aplicando conceitos, representando ideias em diferentes maneiras, articulando conexões ou relacionando um tópico dado com outras ideias." (VAN DE WALLE, 2017, p. 6, tradução nossa).

Esse questionário permitiu verificar que a análise realizada com base nos registros de aula, pela professora e pelos mestrandos, ficou evidente também nas respostas dos estudantes, confirmando que a Matemática ensinada na concepção de Making Sense, contribui para o desenvolvimento de uma cultura de sala de aula que permita a construção colaborativa do conhecimento matemático.

\section{CONSIDERAÇÕES FINAIS}

A Resolução de Problemas como um caminho para se aprender Matemática com compreensão, possibilitou a construção dos conceitos pretendidos, bem como permitiu melhorar as atitudes e convicções dos acadêmicos, que passaram a "[...] desenvolver uma autoimagem positiva sobre a sua habilidade para aprender e compreender matemática" (VAN DE WALLE, 2009, p. 48).

Nesse contexto, cabe ressaltar que a elaboração de problemas que visam a construção de conceitos é uma tarefa que merece atenção por parte do professor, uma vez que dificilmente eles são encontrados de forma imediata em livros didáticos ou outros meios. Desta forma, os problemas devem ser elaborados e pensados pelo professor, de modo a permitirem aos estudantes um caminho de solução a partir dos seus próprios conhecimentos e que, a partir de pesquisas ou troca de ideias com colegas, seja possível estabelecer uma solução, bem como propiciar a aprendizagem de novos conceitos, sendo que a compreensão matemática acontece quando se estabelecem essas conexões.

Além disso, a elaboração dos problemas precisa levar em consideração os anseios e o contexto 
daquele grupo de estudantes em questão, de modo a despertar o interesse e a vontade em resolver, 0 que reitera novamente o papel do professor de desenvolver tais situações.

Outro ponto que merece ser destacado refere-se à correção destas atividades. Diferentemente de uma avaliação resultante de uma metodologia tradicional, na qual o estudante geralmente reproduz técnicas e métodos indicados pelo professor, quando se desenvolve a construção de conceitos através do Making Sense, eles são direcionados a refletir e agir com autonomia e, assim, a correção das atividades demandará de mais tempo, visto que as resoluções possivelmente seguirão caminhos diferentes, sem uma padronização de soluções.

Uma situação que ficou evidente após a aplicação dessas atividades foi que nem todas as dimensões do Making Sense apresentam resultados imediatos. É certo que para iniciar uma prática baseada nesses preceitos, as dimensões referentes a natureza das tarefas de aprendizagem e o papel do professor precisam ser previamente estabelecidas e seguidas. Contudo, a cultura social da sala de aula, bem como 0 senso de equidade, se constitui a partir de um processo constante, que não acontece de uma hora para outra, mas precisam ser incentivados e mediados pelo professor. Por esses motivos, estabelecer uma prática pedagógica estruturada nessas dimensões requer tempo e dedicação, mas pode-se constatar resultados positivos desde a primeira aplicação.

Por fim, para pesquisas futuras sugere-se avaliar as implicações dessa prática para 0 ensino de outros tópicos de matemática mais avançada, com situações envolvendo funções e Cálculo Diferencial e Integral por exemplo, temas que usualmente os estudantes costumam apresentar mais dificuldades de aprendizagem e que estão presentes na maioria dos currículos do curso de Administração.

\section{REFERÊNCIAS}

ALLEVAT0, Norma Suely Gomes. Trabalhar através da Resolução de Problemas: Possibilidades em dois diferentes contextos. VIDYA EDUCAÇÃO, Santa Maria, v. 34, n. 1, p. 209-232, jun. 2014.

ALLEVATO, Norma Suely Gomes; ONUCHIC, Lourdes de La Rosa. Ensino-AprendizagemAvaliação de Matemática: por que Através da Resolução de Problemas? In: ONUCHIC, Lourdes de La Rosa et al. (Org.). Resolução de Problemas: Teoria e Prática. Jundiaí: Paco Editorial, 2014. p. 35-52.

BRASIL. Diretrizes Curriculares Nacionais do curso de graduação em Administração. Brasília: Ministério da Educação, 2005. Disponível em: https://bit.ly/3f38lbh. Acesso em: 02 mai. 2018.

CÂNDID0, P. T. Comunicação em Matemática. In: SMOLE, K. S.; DINIZ, M. I, (Org.). Ler, escrever e resolver problemas: Habilidades básicas para aprender matemática. Porto Alegre: Artmed, 2001. p. 15-28.

HIEBERT, J. et al. Making Sense: Teaching and Learning Mathematics with Understanding. Portsmouth: Heinemann, 1997. $184 \mathrm{p}$.

ONUCHIC, L. de la R. Ensino-Aprendizagem de Matemática Através da Resolução de Problemas. In: BICUD0, M. A. V. (Org.). Pesquisa em Educação Matemática: Concepções e Perspectivas. São Paulo: Editora Unesp, 1999. p. 199-218.

POLYA, G. A arte de resolver problemas. 2. ed. Rio de Janeiro: Interciência, 1995. Tradução e adaptação Heitor Lisboa de Araújo. 
RUPPENTHAL, R.; SCHETINGER, M. R. C. A Argumentação e a Capacidade de Resolver Problemas em Estudantes do Ensino Fundamental. Alexandria: Revista de Educação em Ciência e Tecnologia, Florianópolis, v. 10, n. 2, p. 35-52, nov. 2017. Disponível em: https://bit.ly/3jGiuDX. Acesso em: 08 jun. 2018.

VAN DE WALLE, J. A. Matemática no Ensino Fundamental: Formação de Professores e Aplicações em Sala de Aula. 6. ed. Porto Alegre: Artmed, 2009.

VAN DE WALLE, J. A. Teaching Mathematics for Understanding. In VAN DE WALLE, J. A.; KARP, K.; WILLIAMS, J. M. B.; LOVIN, L. Teaching Student-Centered Mathematics. Pearson, 2017.

VILA, A.; CALLEJO, M. L. Matemática para aprender a pensar: 0 papel das crenças na resolução de problemas. Porto Alegre: Artmed, 2006.

RECEBIDO EM: 09 dez. 2019

CONCLUÍDO EM: 10 fev. 2020 